\title{
A comparative study of Brachychiton populneus seed and seed-fiber oils in Tunisia
}

\begin{abstract}
We conducted a comparative study of two oils extracted from Brachychiton populneus seeds and seed fibers grown in Tunisia. Oil yields from seed and seed fiber were 29.95 and $5.30 \%$, respectively. GC-MS analysis showed that the most abundant fatty acid was linoleic acid (37.91\%) followed by oleic acid (30.67\%) in seeds. In seed fiber, the most abundant were oleic acid $(62.04 \%)$ and linoleic acid (11.90\%). Sterculic acid (7.27\%), a rare fatty acid, was detected in seed oil. Moreover, carotenoid and chlorophyll levels were approximately two-fold higher in seed-fiber oil (39.66 and $1.9 \mathrm{mg} / \mathrm{kg}$ ) than in seed oil (19.48 and $0.78 \mathrm{mg} / \mathrm{kg})$. Tocol contents were more than 10 -fold higher in fiber-seed oil $(979.31 \mathrm{mg} / 100 \mathrm{~g})$ than in seed oil $(83.2 \mathrm{mg} / 100$ g). Furthermore, thermal behavior (TGA and DSC) in both oils, and the antioxidant activity, phenolic content, and oxidative stability at different temperatures in seed oil were evaluated. The results of this study suggest that B. populneus seed oil may have an important role in nonfood applications and that seed-fiber oil is a source of high-value compounds.
\end{abstract}

